\title{
Neurociencia para filósofos: Cómo el estudio del cerebro nos ayuda a comprender el pensamiento
}

\author{
(Neuroscience For Philosophers: \\ How The Study Of Brain Helps Us \\ Understand Thinking)
}

\section{MIGUEL MARTÍ SÁNCHEZ}

Facultad de Filosofía

Universidad de Navarra

mmarti.1@alumni.unav.es

¿Por qué una recensión de un libro sobre la historia de la Neurociencia ${ }^{1}$ en una revista dedicada a las relaciones entre ciencia, fe y Filosofía? No es usual que se reseñen libros sobre la historia de disciplinas científicas, a no ser sobre Física. Como es sabido, el cerebro no deja de ser un órgano corporal del ser humano y de otras especies del reino animal, del mismo modo que el corazón o el estómago. Si a ninguna de las disciplinas que los estudian les presta el filósofo especial atención, pues ¿qué aporta al filósofo un conocimiento de estos órganos o, en general, de lo que sobre ellos dicen

1 Blanco, Carlos. 2014. Historia de la neurociencia. El conocimiento del cerebro y la mente desde una perspectiva interdisciplinar. Madrid: Biblioteca Nueva. 
los especialistas? ¿Qué diferencia hay entre el cerebro y el resto de órganos que conforman el cuerpo humano?

En primer lugar, conviene notar que las funciones que se le atribuyen al cerebro lo convierten en un órgano esencial para comprender al ser humano en sus múltiples manifestaciones: habla, conducta, actuación, etc. De ahí que no se le pueda considerar como una parte entre otras, como podría ser el hígado o el páncreas, sino aquel que prima facie interviene en aquello que, más propiamente, nos hace humanos: la racionalidad y la libertad.

En segundo lugar, conviene tener en cuenta que, al intentar explicar el cerebro, uno se encuentra, al mismo tiempo, frente a lo que podría ser el origen o condición de posibilidad de que podamos conocer el cerebro en cuanto tal. Es decir, debe notarse que al dar cuenta de él debe incluirse la posibilidad de que el cerebro mismo -si se acepta que es aquello que conoce- sea capaz de dar lugar a algo como un "yo" (alguien auto-consciente) que es quién es capaz de "hacer ciencia”.

Por último, como hace notar el autor, el cerebro contribuye de manera insustituible no sólo en la organización, desarrollo y mantenimiento del cuerpo, sino también en la capacidad del ser humano de sentir, hablar, recordar, aprender, conocer e incluso amar. Al decir esto no se busca apoyar sin más un planteamiento materialista o positivista, pero sí advertir que no todo aporte de las ciencias experimentales, en especial los de la Neurociencia, puede rechazarse por el mero hecho de proceder de ella. No basta con poner la etiqueta de psicologismo a cualquier planteamiento que indague los soportes biológicos del conocimiento, siempre y cuando se acuda a ellos para integrarlos en una respuesta a preguntas de tipo filosófico -en el sentido de últimas- como: ¿qué es sentir?, ¿qué es actuar?, ¿qué es recordar?, ¿qué es hablar un lenguaje?

El autor del libro no es sólo un filósofo o sólo un científico. Carlos Blanco (1986-...) ha estudiado Química, Filosofía y también Teología; era además, hasta hace unos meses, investigador en el "Proyecto Mente-Cerebro: biología y subjetividad en la filosofía y la neurociencia contemporáneas” del Instituto Cultura y Sociedad (ICS) de la Universidad de Navarra. Por lo tanto, un ejemplo vivo de interdisciplinariedad. Es cierto que el que se 
decanta por la multidisciplinariedad corre el riesgo de quedar en tierra de nadie, pero al mismo tiempo sólo así se es capaz de elaborar síntesis fecundas, tan necesarias para alcanzar cierta unidad de los saberes. En este caso, la perspectiva interdisciplinar se orienta a bosquejar una interpretación coherente de las relaciones entre mente y cerebro -espíritu y naturaleza, libertad y necesidad-.

El libro consta de tres partes: 1) "Categorías fundamentales de la historia de la Neurociencia”, 2) "Percepción y Neurociencia”, y 3) “La memoria y el aprendizaje, las emociones, el lenguaje y la conciencia: Neurobiología y Psicología cognitiva”.

La primera parte del libro es un acercamiento a los personajes, conceptos, descubrimientos y teorías fundamentales de la historia de lo que desde los años 60 del siglo XX se llama Neurociencia. A través de este recorrido histórico, bien documentado, se asiste a una evolución paulatina, no exenta de errores y equivocaciones, del problema mente-cerebro. Desde la Antigüedad hasta la época contemporánea, se describen los hitos alcanzados en cada momento histórico. Se ofrecen detalles de interés y, sobre todo, se enfatizan los genuinos descubrimientos o cambios de paradigma que han propiciado verdaderos avances en el conocimiento del cerebro y el sistema nervioso.

La tesis de fondo es que no cabe prescindir de casi ninguna de las aportaciones de las distintas ramas de la ciencia -y tampoco de la Psicología y la Filosofía- a la hora de estudiar el cerebro. No obstante se concede especial importancia a la Física, Química y Biología (especialmente celular y molecular) en cuanto únicas ciencias capaces de describir los procesos que subyacen a la mente. Además, en esta primera parte, se distinguen dos posibles enfoques para el acercamiento al estudio del cerebro. Por un lado, la perspectiva reduccionista o "de abajo a arriba", y por otro lado, aquélla que opta por una orientación holística o "de arriba a abajo". Cada una de ellas tiene sus ventajas y sus inconvenientes, y el autor lo hace ver en ambos casos. Al mismo tiempo, parece convencido de la importancia de la primera de ellas. Esto se debe a que, a su juicio, lo contrario supondría renunciar a explicaciones genuinamente científicas en aras de argumen- 
taciones de tipo casi esotérico. Por eso resalta la importancia de que un enfoque holístico no debe prescindir de los resultados alcanzados por la perspectiva reduccionista.

La segunda parte analiza la relación entre Neurociencia y percepción. Como hace notar el autor, la filosofía desde antiguo -piénsese en el tratado De Anima de Aristóteles y antes en las discusiones de Platón en el Teeteto- se preguntó por la percepción, es decir, por el modo en que, por primera vez, el mundo se hace objeto para el ser humano. A partir de los descubrimientos de la Neurociencia contemporánea, se exponen los avances en este campo. Destaca el hecho de que frente a un empirismo radical como el de Berkeley, la psicología de la Gestalt mostró que la percepción se hace con formas y no tanto con partes que luego reconstruya. De ahí que, como repite en varias ocasiones el autor, el problema paradigmático, y todavía un enigma (p. 158), con que se encuentran los neurocientíficos y filósofos enfrascados en explicar las relaciones entre mente y cerebro, sea el de cómo puede percibirse el mundo de manera unitaria cuando son múltiples los estímulos -químicos y eléctricos- que se reciben (p. 175). Es interesante, como también hace notar el autor, que este mismo problema sea ya formulado por Aristóteles mediante el concepto de koiné aisthesis o sentido común (Cfr. De Anima, II).

Frente a lo que podría suponerse, la doctrina de los cinco sentidos no ha sido desbancada por la Neurociencia, más bien, mediante los resultados alcanzados por ella, se ha hecho más sofisticada. El autor prefiere hablar antes que de sentidos de sistemas sensoriales, quizá debido a la increíble complejidad de procesos necesarios para que algo como la simple visión de un paisaje sea posible tal y como la observamos. En este sentido, la intervención de los miembros corporales externos (oreja, ojos, etc.) -con sus múltiples partes no visibles a primera vista- está estrechamente relacionada con la actividad cerebral y el sistema nervioso; pues sin el acompañamiento de ésta sería imposible la percepción unitaria del mundo. De modo que, al parecer, el cerebro juega un papel parecido al de los sentidos internos descritos por la escolástica. Para ésta, la ausencia de éstos haría imposible que el mundo fuese objeto como lo es para el ser humano en cuanto 
ser contingente y temporal. No sólo porque está, de hecho, dotado de imaginación y memoria sino también porque como afirma la Filosofía, y en esto coincide con la Neurociencia, existe la llamada cogitativa. La moderna investigación cerebral se muestra así sensible a la problemática de cómo hay factores no meramente mecánicos que intervienen en la formación de nuestro conocimiento.

Durante esta parte del libro dedicada a la relación de percepción y cerebro, el autor remite varias veces a la filosofía de I. Kant y al modo en que ésta intenta abordar el problema de la génesis del conocimiento objetivo para la conciencia ("Ich denke”). Lo hace porque cree descubrir un puente entre este planteamiento y el de la moderna Neurociencia. No obstante, conviene no olvidar que tal interpretación es susceptible de conducir a errores pasados. Si no se es cuidadoso con el apriorismo y si, además, éste es entendido no al modo racionalista de las ideas innatas sino como una cierta dotación natural previa ("El <<punto crítico >> entre percibir una forma y no hacerlo no responde tanto a una mera asociación de estímulos como a una estructuración previa, <<apriorística〉>, indudablemente plástica y modelada por la experiencia social, pero cuya base nos viene dada, en gran medida, por la constitución de nuestro sistema nervioso”, p. 145), es fácil reponer doctrinas de corte psicologista o fisicalista, que -como es sabido- hacen surgir a los objetos psíquicos de los procesos químico-eléctricos (aunque para ello fuese necesaria también la intervención de estímulos venidos del exterior). De todos modos, el autor parece ser consciente de esta disyuntiva.

La tercera parte del libro, a mi juicio la más relevante, aborda los avances de la Neurociencia en la explicación de manifestaciones humanas de enorme relevancia para la comprensión de nosotros mismos como son: la memoria, el aprendizaje, las emociones, el lenguaje y la conciencia. Frente a la imagen de una ciencia empírica ajena a las múltiples interpretaciones, incertidumbres y ambigüedades - tan comunes y positivas en las humanidades-, el autor ofrece una imagen de ella -sobre todo de la Neurociencia- más bien auspiciada por los enigmas y misterios.

¿Qué puede decirnos el estudio del cerebro acerca de, por ejemplo, el lenguaje o las emociones? Como es sabido, aunque los animales superiores 
comparten varias de éstas características lo hacen de manera diferente a como las tienen los humanos. Sin embargo, es esta participación la que incita al neurocientífico a buscar semejanzas entre ellos, y por lo tanto, a descubrir las bases neurológicas de todas esas manifestaciones. De importancia capital es el descubrimiento de la plasticidad cerebral. Según esta tesis, no sólo la dotación biológica inicial sino también el mundo exterior es causa de que el cerebro -en sus diversas etapas de crecimiento- llegue a ser el que es y haga posible lo que hace, a saber: ser condición de posibilidad de percibir, memorizar, aprender, etc. Es interesante señalar que hay una relación estrecha, indicada por el propio autor (pp. 90-91, nota 12), entre esta temática y la llamada experiencia (empeiria) -irreductible a una génesis a partir del esquema estímulo-respuesta-, que tanta repercusión tuvo (y tiene) en la filosofía de corte realista (Cfr., por ejemplo Aristóteles, Metaphysica, I, 980a1-981b9).

En cuanto al tema de las emociones, el autor señala que la moderna Neurociencia no ha hecho sino confirmar que es imposible separar a éstas de la corporalidad (p. 217). Junto a esto, la Neurociencia ha contribuido, a su manera, a desbancar una visión de la razón, que la situaría más allá del cuerpo, como si estuviese desgajada de cualquier relación con las emociones. Más bien, la visión que arrojan las investigaciones neurocientíficas es la de una razón que piensa con y desde las emociones. En este punto, a mi juicio, sería útil -con el fin de continuar el diálogo entre Filosofía y Neurociencia- distinguir entre razón práctica y razón teórica. Es claro que la primera cuenta en todo momento con las emociones y demás pasiones, en cuanto que "circunstancias" a tener en cuenta en la deliberación y en la posterior acción (piénsese en el papel de la órexis para la acción en Aristóteles, cfr. De Anima, III, 9). Sin embargo, la conexión de las emociones con la razón teórica me parece más difícil de “dibujar”.

Como advierte el propio ensayista, el lenguaje supone el ser capaz de una integración complejísima de elementos diferentes; esto es necesario no sólo para explicar su combinación (sintaxis) sino para hacerlo con sentido o significado (semántica). Aunque la Neurociencia está lejos de encontrar una respuesta satisfactoria a estas cuestiones, la interdisciplinariedad 
para el estudio del lenguaje, que supone el intercambio de experiencias entre filólogos, psicólogos, científicos computacionales, neurólogos, etc., ya ha empezado a dar sus frutos.

No obstante, en el caso del lenguaje, queda abierto el interrogante de si basta con la interacción entre cerebro y mundo externo para hablar tanto de su aprendizaje como de su producción. Aún así, el autor parece decantarse por una opinión afirmativa, es decir, según él, es posible explicar el aprendizaje del lenguaje sin necesidad de "recurrir a una supuesta capacidad de abstracción” (p. 226). Pienso que a esto podría objetarse que ya la moderna filosofía del lenguaje (por ejemplo Frege) -y antes de ella, filósofos como Platón y Aristóteles- mostraron que para hablar de palabra parece necesario admitir que un componente inmaterial es añadido a la voz emitida, en el caso del lenguaje hablado, y al signo escrito, en el caso del lenguaje escrito, (Cfr. Aristóteles, Metaphysica, 1253a11-18). Lo que conduce directamente al problema de los universales y, de manera indirecta, al de la intencionalidad.

Esto no significa reducir al mínimo las aportaciones que a este campo pueden hacerse desde la neurobiología. A fin de cuentas, una mayor profundización en el origen animal del lenguaje no puede sino ayudar a observar mejor las convergencias entre el lenguaje humano y el modo de expresarse de las voces animales, y con ello, al mismo tiempo, advertir sus diferencias.

Como han puesto de relieve varios científicos destacados, el problema de las relaciones entre cerebro y conciencia es el principal misterio con el que se enfrenta la moderna Neurociencia. Como escribe Blanco: "La capacidad de reflexionar sobre uno mismo y de captar la experiencia del mundo como propia probablemente represente el fenómeno más complejo que acontece en el seno del universo físico" (p. 235). El dilema entre materialismo e idealismo se hace aquí concreto y por eso se vuelve imprescindible la colaboración entre las distintas ramas del saber, es decir, la colaboración de lo que se han llamado las "dos culturas". Tanto una como otra perspectiva tomadas por separado son insuficientes: por un lado, el cientifismo cae en un craso materialismo, incapaz de ir más allá de la descripción de la 
conciencia como adquisidora de datos y gestora de ellos, sin advertir que la conciencia propiamente lo que hace es interpretarlos y darles significado; por otro lado, el idealismo se cierra en banda y es incapaz de integrar los resultados científicos en una visión coherente con sus postulados, con la única solución de desacreditar -normalmente de manera arbitraria- cualquier aportación neurocientífica o incluso científica, en general.

Al final del libro, mediante un excursus, Blanco intenta condensar el status quaestionis del problema mente-cerebro. En su opinión, es un problema que sólo se puede solucionar científicamente (p. 261), porque la filosofía ha cedido el testigo de las genuinas explicaciones racionales a la ciencia empírica. Ahora bien, creo que las ciencias sociales tienen el deber de hacer reflexionar a la humanidad sobre el significado que para la vida humana, en general, tienen esos resultados.

Tras el recorrido por la historia de la Neurociencia, al lector se le introduce en las posibles explicaciones-marco del problema mente-cerebro. Éstas, en el fondo, si nos situamos en un punto de vista estrictamente científico, son sólo hipótesis. Sin embargo, condensan de manera clara y concisa cuáles son las opiniones dominantes sobre éste problema que se tienen en cuenta como razonables en el ámbito científico. Cierran el libro diez puntos breves donde el autor argumenta acerca de la necesidad de que la filosofía preste atención a la Neurociencia. Ante todo, porque teniendo el problema mente-cerebro un origen filosófico, es dudoso que pueda resolverse sólo desde la Filosofía.

En cuanto al modo en que Blanco entiende qué es la filosofía, quisiera expresar mi parcial desacuerdo con su visión. Es obvio que escribir un libro exige tomar partido, es decir, dar por sentadas algunas cosas, de otro modo serían necesarias infinitas explicaciones. Como no podía ser de otra manera, esto ocurre en el texto de Carlos Blanco, sobre todo al hablar de la filosofía en cuanto tal. En este caso, me parece que el uso que hace Blanco de la filosofía, le lleva a confundir a ésta con una cierta especulación o reflexión con el fin de elaborar una cosmovisión, pero sin pretensión de genuino conocimiento; como mucho se le puede pedir que sea una suerte de ética. Por consiguiente, la filosofía debería acompañar a la ciencia, pero 
en ningún caso, parece ser, contribuir con sus propios descubrimientos, o bien oponerse, cuando fuese necesario, a la ciencia e incluso criticarla. Este concepto de filosofía es, en mi opinión, demasiado pobre. Y esto hace que el libro de Carlos Blanco no pueda considerarse un libro de filosofía. Es un libro de alguien que reconoce a la filosofía sus méritos pasados, e incluso le concede todavía cierta autoridad, pero parecida a la que se da al antiguo jefe de la empresa, es decir, aquél que, a pesar de que las cosas han cambiado y se ha quedado atrasado, se le toleran las excentricidades y opiniones pasadas de moda.

A mi juicio, y como han puesto de relieve numerosos filósofos, forma parte esencial de la investigación filosófica el preguntarse simultáneamente por el método de la filosofía misma (piénsese en Sócrates y discípulos, o también en Hegel, Husserl o Heidegger). Por eso, se la puede definir como aquel saber que aspira a ser un conocimiento carente de presupuestos. Lo cual sucede en cuanto que se pregunta de manera radical por el origen de las cosas -incluido el ser humano mismo y su conocimiento-, de modo que, entre otras preguntas, no puede renunciar a cuestionarse también de qué manera conoce lo que conoce, o con otras palabras, a preguntarse ¿qué es conocer? o ¿qué es el conocimiento? Desde el momento en que Blanco renuncia a hacerse estas preguntas da por supuesto que conoce o que se conoce la respuesta. En mi opinión, esto es algo incompatible con el auténtico filosofar.

Sí es, en cambio, un libro de extraordinario interés para filósofos, y ello por varias razones: 1) porque contribuye -mediante el recurso a los descubrimientos científicos- a que se formulen de manera correcta las preguntas filosóficas, sobre todo, las que conciernen a la relación de lo mental con lo físico; 2) porque, al estar escrito por un filósofo y un científico, elabora explicaciones en las cuales los descubrimientos científicos se integran dentro de una reflexión más amplia, cabe decir interdisciplinar, que tiene en cuenta las limitaciones de la ciencia y la existencia de otras realidades como el arte; y 3) porque es un libro bien escrito y documentado, que hace pensar y es sugerente. 
MIGUEL MARTÍ SÁNCHEZ

\section{Referencias}

Aristóteles. De Anima.

-.Metaphysica.

Blanco, Carlos. 2014. Historia de la neurociencia. El conocimiento del cerebro y la mente desde una perspectiva interdisciplinar. Madrid: Biblioteca Nueva. 